\title{
Result of intravitreal aflibercept injection for myopic choroidal neovascularization
}

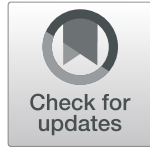

Shih-Lin Chen ${ }^{1}$, Pei-Ling Tang ${ }^{2}$ and Tsung-Tien Wu ${ }^{1,3^{*}}$

\begin{abstract}
Background: The current study aimed to evaluate the efficacy of intravitreal aflibercept injections as the primary treatment for subfoveal/juxtafoveal myopic choroidal neovascularization (CNV) by using optical coherence tomography (OCT). Optical coherence tomography angiography (OCTA) was further used for some patients to detect the changes of CNV after treatment.

Methods: In the present study, 21 treatment-naive eyes of 21 patients with subfoveal/juxtafoveal myopic CNV received primary intravitreal aflibercept injections and were under follow-up for a minimum duration of 12 months. Among the 21 patients, 12 underwent OCTA to evaluate the changes in central foveal thickness, selected CNV area, and flow area.

Results: The mean best-corrected visual acuity (BCVA) pertaining to all the patients significantly improved from the baseline value of 0.7 to $0.3 \log M A R$ after treatment for 12 months $(P=0.001)$. However, the improvements in the median BCVA after treatment for three and 12 months were not statistically significant in the younger group $(<50$ years), compared to the older group ( $\geq 50$ years). One aflibercept injection resolved the CNV in $47.6 \%(10 / 21)$ of the patients. The younger group displayed greater improvement in the median central foveal thickness, compared to the older group.

OCTA revealed interlacing or disorganized pattern at the level of the outer retinal layer in 12 subjects with myopic CNV. After 3 months of treatment, both groups displayed a decrease in the size of the selected CNV area and flow area. The interlacing group displayed a trend towards better anatomical improvements.
\end{abstract}

Conclusion: Intravitreal aflibercept injection provides long-term improvement in visual acuity in patients with myopic CNV. Eyes with the interlacing pattern on OCTA displayed a greater decrease in size and flow after aflibercept injection.

Trial registration: Before data collection, written informed consent was obtained from each participant, whose identity information was protected by encryption and conversion to a non-identifiable format and removing data links. This study was approved by the Institutional Review Board of Kaohsiung Veterans General Hospital (KSVGH21(T1-17).

Keywords: Aflibercept, Choroidal neovascularization, High myopia, Optical coherence tomography angiography

\footnotetext{
* Correspondence: ttwu0101@gmail.com

'Department of Ophthalmology, Kaohsiung Veterans General Hospital,

No.386, Dazhong 1st Rd., Zuoying Dist., 813 Kaohsiung, Taiwan

${ }^{3}$ School of Medicine, National Yang Ming University, Taipei, Taiwan

Full list of author information is available at the end of the article
}

(c) The Author(s). 2021 Open Access This article is licensed under a Creative Commons Attribution 4.0 International License, which permits use, sharing, adaptation, distribution and reproduction in any medium or format, as long as you give appropriate credit to the original author(s) and the source, provide a link to the Creative Commons licence, and indicate if changes were made. The images or other third party material in this article are included in the article's Creative Commons licence, unless indicated otherwise in a credit line to the material. If material is not included in the article's Creative Commons licence and your intended use is not permitted by statutory regulation or exceeds the permitted use, you will need to obtain permission directly from the copyright holder. To view a copy of this licence, visit http://creativecommons.org/licenses/by/4.0/. The Creative Commons Public Domain Dedication waiver (http://creativecommons.org/publicdomain/zero/1.0/) applies to the data made available in this article, unless otherwise stated in a credit line to the data. 


\section{Background}

Pathologic myopia is defined as a refractive error of 6.0 diopters or worse spherical equivalent, accompanied by the characteristic degenerative changes in the sclera, choroid, and retinal pigment epithelium, with severe visual impairment $[1,2]$. The Asian population displays a higher prevalence of pathologic myopia, ranging from 0.9 to $3.1 \%$, compared to other regions of the world. Pathologic myopia has been reported to be the major cause of visual impairment or low vision in 12 to $27 \%$ of the Asian population [3-5].

The complications associated with pathologic myopia include posterior staphyloma, myopic maculopathy, myopic choroidal neovascularization (CNV) [1]. Myopic $\mathrm{CNV}$ is one of the most common complications associated with the aforementioned condition that may cause severe visual impairment [6]. It has been estimated that 5.2 to $11.3 \%$ of the patients with pathologic myopia will develop myopic CNV and the natural course and prognosis of subfoveal CNV are generally poor [3, 7-9].

Currently, therapy involving the intravitreal injection of anti-vascular endothelial growth factors (VEGFs), such as bevacizumab, ranibizumab and aflibercept, is widely used for the treatment of myopic CNV [10-17]. Recently, aflibercept, a novel recombinant fusion protein binding all isoforms of VEGF, was approved for the treatment of CNV secondary to pathologic myopia, following the well-tolerated and effective results demonstrated by the MYRROR study [18]. Traditionally, the diagnosis of myopic CNV relied on fundus fluorescein angiography, indocyanine green angiography, and optical coherence tomography (OCT). Optical coherence tomography angiography (OCTA) is a recent, noninvasive method without dye injection, which provides a layered image to observe the different shapes and sizes of CNV [19-21]. The ability of OCTA to detect the morphological features of myopic $\mathrm{CNV}$ have been reported by few studies [22]. A previous study used OCTA to assess the therapeutic effects of intravitreal ranibizumab injection on myopic CNV [19]. Current study is the first one to assess the one-year visual outcomes in patients with myopic CNV who underwent treatment with aflibercept and evaluations using OCTA.

\section{Methods}

The current, retrospective study involved the patients with subfoveal/juxtafoveal CNV secondary to pathologic myopia who received intravitreal aflibercept injections. The patients underwent treatment during the time period from August 2015 to June 2020 in the Department of Ophthalmology, Kaohsiung Veteran General Hospital, Taiwan. Informed consent was obtained from all the patients. The study program was reviewed and approved by the Institutional Review Board of Kaohsiung Veterans General Hospital (KSVGH21-CT1-17).

The study included 21 patients with pathologic myopia and subfoveal/juxtafoveal CNV. The inclusion criteria included the following: treatment-naïve patients who were under follow-up for a minimum of 12 months; myopia with a spherical equivalent refractive error $\leq-6 \mathrm{D}$ or axial length $\geq 26.5 \mathrm{~mm}$; active $\mathrm{CNV}$ secondary to pathologic myopia defined as presence of leakage from $\mathrm{CNV}$ seen by fluorescein angiography, and presence of intraretinal edema or subretinal fluid (SRF) or increase of central foveal thickness (CFT) seen by spectraldomain optical coherence tomography (SD-OCT); subfoveal/juxtafoveal CNV; and a best corrected visual acuity (BCVA) of 20/800 or greater. The exclusion criteria included the following: prior treatments for $\mathrm{CNV}$, including PDT and thermal laser photocoagulation; history of intraocular surgery, except cataract surgery; extrafoveal $\mathrm{CNV}$; $\mathrm{CNV}$ secondary to ocular pathology other than pathologic myopia, such as age-related macular degeneration, choroiditis, angioid streaks, or trauma; and hereditary diseases in the eye under investigation or the contralateral eye [23].

Complete ophthalmic examinations were performed at the baseline and all subsequent visits, which included Snellen BCVA (converted to the logarithm of the minimum angle of resolution; logMAR), slit-lamp biomicroscopy, tonometry, fundus examination, fluorescein angiography, and SD-OCT (RTVue XR Avanti with AngioVue, Optovue, Inc., Fremont, CA).

OCTA was conducted using RTVue XR Avanti with AngioVue at $70000 \mathrm{~A}$-scans per second containing $304 \times 304$. The $3 \times 3 \mathrm{~mm}$ scanning area focused on the macula and was acquired using the split-spectrum amplitude-decorrelation angiography technique. The OCTA images were automatically divided into four layers: superficial, deep, outer retina, and choroid capillaries [19]. Automatic retinal segmentation was performed using the software in the machine. Four retinal layers are classified by the software: the superficial vascular plexus (from the inner limiting membrane to the inner plexiform layer), the deep vascular plexus (between the inner and outer boundaries, respectively, at 15 and $70 \mathrm{~mm}$ beneath the inner plexiform layer), the outer retina (from the axonal outer plexiform layer to the Bruch membrane), and the choriocapillaris (from 31 to $59 \mathrm{~mm}$ inferiorly to the RPE). OCTA images were collected at the level of the outer retinal layer.

However, distortion of the retinal tissue boundaries resulted from high myopia often makes automated boundary segmentation more difficult. Manual segmentation and adjustment by the clinician were necessary at times to identify the neovascular network. The CNV area was manually contoured and measured in $\mathrm{mm} 2$ using the 
internal software of the device. Then, the flow area of the area selected manually was measured automatically in $\mathrm{mm} 2$, too. The values pertaining to the selected $\mathrm{CNV}$ areas were recorded, according to the selected size of $\mathrm{CNV}$. The values pertaining to the flow area of CNV were automatically measured from the flow signals detected within the selected area. All the patients underwent OCT and OCTA prior to injection, and after one, three, and 12 months after the injection. The current study excluded the data pertaining to nine of the 21 patients, on account of poor quality or loss of original image from the database, which made further analysis impractical. Intravitreal injections of aflibercept $2 \mathrm{mg}$ were administered under aseptic conditions using a 30gauge needle, $3.5 \mathrm{~mm}$ or $4 \mathrm{~mm}$ from the limbus. Retreatment using aflibercept was performed on the basis of at least one of following observations: an increase in the central foveal thickness (CFT) of more than $50 \mu \mathrm{m}$ between successive examinations, new or persistent cystic retinal changes, subretinal fluid, and new or persistent $\mathrm{CNV}$ on OCT or hemorrhage.

Continuous variables with normal distribution were described as mean and standard deviation, and continuous variables with non-normal distribution were described as median and interquartile range (IQR). An analysis of the normality of independent variables in the different groups (using the Shapiro-Wilk test) revealed that the results of the current study do not follow a normal distribution. Paired data were analyzed using the Wilcoxon signed-rank and two-way ANOVA (Friedman) tests. The significance of the differences between the values pertaining to the study groups were evaluated through further analysis. A significance level of 5\% was adopted for the decision-making in statistical tests. Data were analyzed using the SPSS version 22.0 (IBM Corporation, Armonk, NY, USA).

\section{Results}

The study involved 21 eyes pertaining to 21 patients (15 females and 6 males). The baseline clinical characteristics pertaining to the aforementioned patients are shown in Table 1. The baseline mean age pertaining to all the patients included in the present study $( \pm$ standard deviation $[S D])$ was 51 years ( \pm 18.5 years; range: 43 to 61.5 years). The present study detected CNV in thirteen right eyes $(61.9 \%)$ and eight left eyes $(38.1 \%)$. The mean axial length was $29.34 \mathrm{~mm}( \pm 2.72 \mathrm{~mm}$; range: 28.08 to 30.80 $\mathrm{mm})$. The mean duration of follow-up was 16.6 months.

The study observed that myopic CNV resolved in 10 of the 21 patients (47.6\%) after one aflibercept injection. Furthermore, among the 21 patients under study, nine (42.9\%) received two aflibercept injections and two (9.5\%) received three aflibercept injections during the follow-up (mean of two aflibercept injections per
Table 1 Baseline demographic and clinical characteristics pertaining to all the patients

\begin{tabular}{|c|c|}
\hline \multirow[t]{2}{*}{ Characteristics } & \multirow{2}{*}{$\begin{array}{l}N=21 \\
\text { n (\%)/Md } \pm \text { IQR [range] }\end{array}$} \\
\hline & \\
\hline Age (y) & $51.00 \pm 18.50[43.00-61.50]$ \\
\hline \multicolumn{2}{|l|}{ Age } \\
\hline$\leqq 50$ & $10(47.6)$ \\
\hline$>50$ & $11(52.4)$ \\
\hline \multicolumn{2}{|l|}{ Sex } \\
\hline Male & $6(28.6)$ \\
\hline Female & $15(71.4)$ \\
\hline \multicolumn{2}{|l|}{ Laterality } \\
\hline OD & $13(61.9)$ \\
\hline OS & $8(38.1)$ \\
\hline $\mathrm{AXL}(\mathrm{mm})$ & $29.34 \pm 2.72[28.08-30.80]$ \\
\hline \multicolumn{2}{|l|}{$\mathrm{AXL}(\mathrm{mm})$} \\
\hline$<30$ & $13(61.9)$ \\
\hline$\geqq 30$ & $8(38.1)$ \\
\hline \multicolumn{2}{|l|}{ CNV location (mm) } \\
\hline Subfoveal & $16(76.2)$ \\
\hline Juxtafoveal $<200$ & $5(23.8)$ \\
\hline Number of injections & $2.00 \pm 1.00[1.00-2.00]$ \\
\hline \multicolumn{2}{|c|}{ Number of injections and patients } \\
\hline Once & $10(47.6)$ \\
\hline Twice & $9(42.9)$ \\
\hline Three times & $2(9.5)$ \\
\hline
\end{tabular}

AXL Axial length, CNV Choroidal Neovascularization, IQR Interquartile range, JUXTA Juxtafoveal, Md Median, OD Oculus Dexter, OS Oculus Sinister, SUBF Subfoveal

patient). In addition, among the 11 patients who required more than one injection, 10 patients received the second injection within 3 months after the primary injection and only a single patient received a third injection 6 months after the second injection (Fig. 1).

In all the patients, the mean CFT was observed to decrease significantly from the baseline value of $285.5 \mu \mathrm{m}$ to $249 \mu \mathrm{m}$ after 12 months $(P=0.009)$. The mean BCVA ( \pm standard deviation; SD) significantly improved from the baseline value of 0.7 to $0.39 \log$ MAR after 3 months, and $0.3 \operatorname{logMAR}$ after 12 months $(P=0.001)$ (Table 2). The greatest improvement in visual acuity within the first 3 months after the initial aflibercept injection, and the BCVA remained stable 12 months after the injection.

Further analysis of the 21 eyes revealed that 10 eyes belonged to the patients below the age of 50 years and 11 eyes belonged to patients above or at the age of 50 years. The improvement in median CFT was greater in the younger group ( $<50$ years), compared to the older group $(\geq 50$ years $)(-52 \mu \mathrm{m}$ against $-30 \mu \mathrm{m}$, 


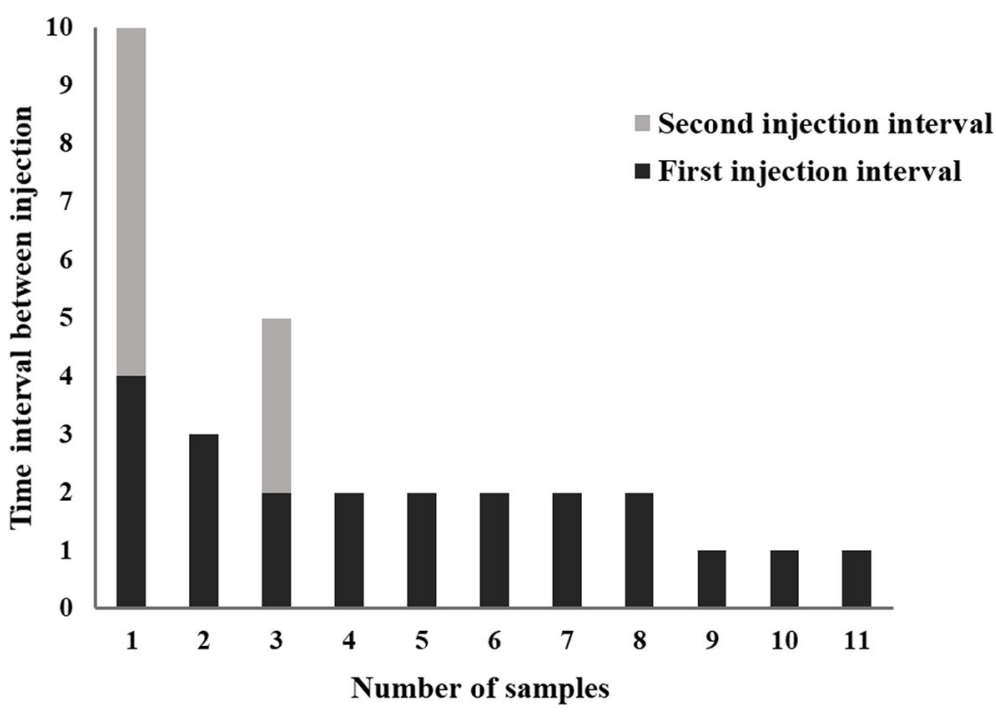

Fig. 1 Among the eleven patients who required more than one injection, ten patients received the second injection within three months after the initial injection. Only a single patient received a third injection after a time interval of more than 3 months

respectively; $P=0.038$ ) (Table 3 ). However, the improvement in median BCVA at the third and twelfth months were not statistically significant in the younger group, compared to the older group (-0.42 logMAR against $-0.34 \log$ MAR, respectively; $P=0.0832$ ) (Fig. 2).

A comparison of the therapeutic effects of intravitreal aflibercept injection between the two groups of patients with axial length below or above $30 \mathrm{~mm}$ using the Mann-Whitney $\mathrm{U}$ test revealed that the improvement in median CFT and BCVA, in the two groups at the third and twelfth months, were not statistically significant (Table 4, Fig. 3).

Myopic CNV presented as an irregular or round, closed lesion at the outer retinal layer on OCTA. This study identified two neovascular patterns: interlacing and disorganized patterns. In the interlacing pattern, which was observed in six among the twelve eyes (50\%), OCTA images revealed dense vascular hyperintensity with a well-circumscribed appearance (Fig. 4). This pattern revealed a high-flow network, comprising a small capillary with a feeder vessel and small capillary ramifications. In the disorganized pattern, which was observed in six among the twelve eyes (50\%), OCTA images revealed a small, high-flow network, harboring a vascular loop-like pattern with no obvious capillary ends (Fig. 5).

The OCTA images revealed changes in the group of eyes with the interlacing $\mathrm{CNV}$ after intravitreal aflibercept injection. One month after the treatment, shrinkage of peripheral vascularity and reduction in vessel density from previous, dense, hyperintense vascularity with wellcircumscribed interlacing lesion was observed. The CNV lesion displayed a greater decrease in size and vessel density after 12 months (Fig. 4). In the group of disorganized CNV, OCTA showed shrinkage of the lesion 1 month after treatment. Reduction in vessel density from a small, high-flow network, harboring a vascular loop-

Table 2 Clinical characteristics pertaining to all the patients at the baseline and 12 months after the administration of the primary aflibercept injection

\begin{tabular}{llll}
\hline Parameter & Median & IQR [range] & Min-Max \\
\hline $\begin{array}{l}\text { Median central foveal thickness }(\mu \mathrm{m}) \\
\text { Baseline }\end{array}$ & 285.50 & $41.5[265-306.5]$ & $222-437$ \\
$\begin{array}{l}12 \text { months after aflibercept injection } \\
\text { BCVA (logMAR) }\end{array}$ & 249.00 & $54[223-277]$ & $188-466$ \\
Baseline & 0.700 & $0.5[5-1.0]$ & $0.009^{\text {a }}$ \\
Three months after aflibercept injection & 0.39 & $0.3[0.2-0.5]$ & $0.16-0.70$ \\
Twelve months after aflibercept injection & 0.300 & $0.28[0.16-0.44]$ & $0.05-0.70$ \\
\hline
\end{tabular}

BCVA best-corrected visual acuity, IQR interquartile range, Max maximum, Min minimum

${ }^{a}$ Wilcoxon signed-rank test

${ }^{\mathrm{b}}$ Friedman two-way ANOVA test 
Table 3 Comparison between the younger group ( $\leqq 50$ years) and older group (>50 years) regarding the changes in median CFT and BCVA (logMAR)

\begin{tabular}{|c|c|c|c|c|c|c|c|}
\hline \multirow[t]{2}{*}{ Parameter } & \multicolumn{2}{|r|}{$\leqq 50$ years } & \multicolumn{4}{|c|}{$>50$ years } & \multirow[t]{2}{*}{$p^{a}$} \\
\hline & Median & IQR [range] & Min-Max & Median & IQR [range] & Min-Max & \\
\hline Change in median CFT $(\mu \mathrm{m})$ & -52.00 & $78.75[-106.75--28.00]$ & $-109-4.00$ & -30.00 & $26[-33.00--7.00]$ & $-1.28--0.10$ & 0.038 \\
\hline \multicolumn{8}{|l|}{ Change in BCVA (logMAR) } \\
\hline Three months after aflibercept injection & -0.42 & $0.88[-0.78--0.10]$ & $-1.10-0.01$ & -0.30 & $0.36[-0.46--0.10]$ & $-1.28--0.10$ & 0.831 \\
\hline Twelve months after aflibercept injection & -0.42 & $0.71[-0.81--0.10]$ & $-1.25-0.16$ & -0.34 & $0.64[-0.84--0.20]$ & $-73.00-45.00$ & 0.832 \\
\hline
\end{tabular}

Mann-Whitney $U$ test

$B C V A$ best-corrected visual acuity, IQR interquartile range, Max maximum, Min minimum

like pattern with no obvious capillary ends was also observed in theses lesions. The CNV lesion showed a greater decrease in size and vessel density after 12 months (Fig. 5).

Three and twelve months after the primary injection, the size of the selected CNV area and the flow area revealed a trend towards decline in both the interlacing pattern and the disorganized pattern (Table 5) (Fig. 6(a)(b)). The interlacing pattern displayed a trend towards better improvement in the size and flow of the selected CNV area (Fig. 6(a)(b)). However, the present study did not observe any obvious difference between the two groups with different patterns with regard to the improvement in BCVA after intravitreal aflibercept injection (Table 5).

\section{Discussion}

In the current study, most eyes showed improvement in vision and the burden of intravitreal therapies was found similar to the MYRROR study, which revealed that the patients with myopic $\mathrm{CNV}$ who underwent intravitreal aflibercept injection displayed significant improvements in visual and anatomic parameters over a time period of 48 weeks [18].

After intravitreal aflibercept injections, the subjects in the younger group displayed a greater reduction in CFT at 12 months compared to the order group. The aforementioned observation was concordant with the clinical findings reported by Yoshida et al. and Bruè et al. [7, 24] At 3 and 12 months, the younger group displayed a trend towards better improvement in vision after intravitreal aflibercept injections, although the results were not statistically significant.

A less reduction in CFT at 12 months after treatment associated with myopic $\mathrm{CNV}$ in the older age group could be attributed to the decreased integrity and function of the myopic retinal pigment epithelium that downgrades the inhibition of angiogenesis [25]. Indeed, some studies report that myopic CNV in older patients could manifest simultaneous AMD and high myopia, resulting in poor natural outcomes. Moreover, older patients tend to develop chorioretinal atrophy or degeneration that negatively influences the final visual acuity. However in our study, no statistically significant
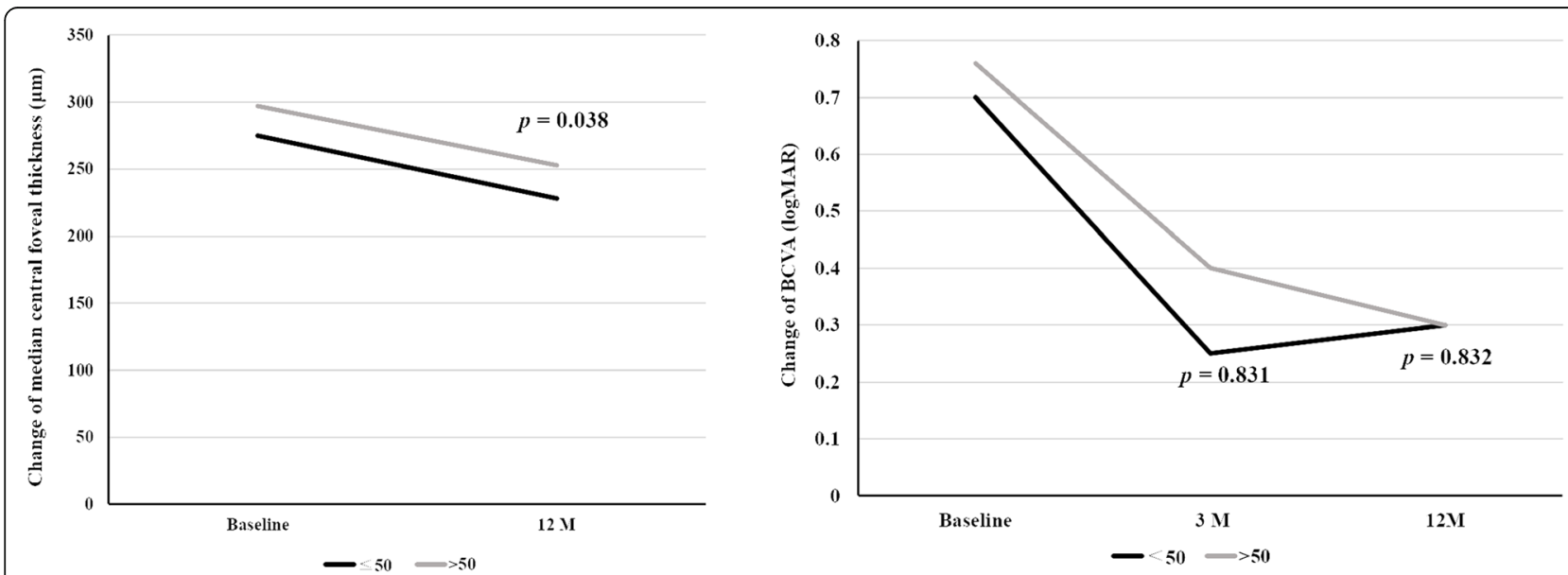

Fig. 2 Both the younger ( $<50$ years) and older ( $\geq 50$ years) groups displayed improvement in the median CFT and BCVA (logMAR). MannWhitney $U$ test revealed that the improvement in median central foveal thickness was greater in the younger group, compared with the older group at the twelfth month ( -52 um against -30 um, respectively; $p=0.038)$. However, the improvement in median BCVA (logMAR) in the two groups, at the third and twelfth months, were not statistically significant $(-0.42 \log M A R$ against $-0.34 \log M A R$, respectively; $P=0.0832)$ 
Table 4 Comparison between the two groups with $A X L<30 \mathrm{~mm}$ and $A X L \geqq 30 \mathrm{~mm}$ regarding the changes in median CFT and $B C V A$ (logMAR)

\begin{tabular}{|c|c|c|c|c|c|c|c|}
\hline \multirow[t]{2}{*}{ Parameter } & \multicolumn{3}{|c|}{$\mathrm{AXL}<30 \mathrm{~mm}$} & \multicolumn{3}{|c|}{$A X L \geqq 30 \mathrm{~mm}$} & \multirow[t]{2}{*}{$p^{a}$} \\
\hline & Median & IQR [range] & Min-Max & Median & IQR [range] & Min-Max & \\
\hline Change in median CFT $(\mu \mathrm{m})$ & -32.00 & $59.00[-64.00--5.00]$ & $-109.00-45.00$ & -45.50 & $77.75[-97.75--20]$ & $-109--7.00$ & 0.246 \\
\hline \multicolumn{8}{|l|}{ Change in BCVA (logMAR) } \\
\hline Three months after aflibercept injection & -0.30 & $0.48[-0.58--0.10]$ & $-1.28-0.01$ & -0.48 & $0.51[-0.74--0.23]$ & $-1.10--0.1$ & 0.276 \\
\hline Twelve months after aflibercept injection & -0.30 & $0.66[-0.81--0.15]$ & $-1.28-0.16$ & -0.52 & $0.50[-0.83--0.33]$ & $-1.25--0.10$ & 0.274 \\
\hline
\end{tabular}

BCVA best-corrected visual acuity, IQR interquarti

${ }^{a}$ Mann-Whitney $\mathrm{U}$ test

difference in BCVA changes at 12 months after treatment between younger and older group is noted.

Previous studies reported that the role of spherical equivalent refraction and axial length as predictive factors associated with the final visual acuity after antiVEGF treatment in myopic CNV remained controversial. Bruè et al. reported that higher myopia is associated with decreased visual acuity after intravitreal aflibercept injections in young patients with myopic CNV. Some studies identified a significant positive correlation between BCVA and macular choroidal thickness after anti-VEGF treatment [23]. Greater axial length was often considered to be major factor associated with macular choroidal thinning. The current study did not observe any difference in the treatment outcomes between the groups with long and short axial length (Table 4). This could be attributed to the relatively small sample size and short duration of follow-up. Further investigations should be performed to elucidate the significance of axial length in predicting treatment outcomes.
Recently, OCTA is being widely used in the diagnosis of various macular diseases and provides detailed, layered images of enface retinal and choroidal vasculature [26-29]. Cheng et al. used OCT B-scan and OCTA to perform quantitative analysis and monitor the therapeutic effects of intravitreal ranibizumab injection $(0.5$ mg/0.05 mL) (Lucentis; Genentech, Inc., South San Francisco, CA) in myopic CNV [19]. The OCTA revealed significant attenuation of the capillaries and small caliber feeder vessels after intravitreal ranibizumab injection. Moreover, the study reported a simultaneous reduction in the size of the selected CNV area and flow area.

To the best of our knowledge, this is the first study that used OCTA to detect the changes in the shape, selected area, and flow area of CNV after intravitreal aflibercept injection at 3 and 12 months. In the current study, among twelve patients who underwent OCTA, eleven patients displayed improvement in BCVA and twelve patients displayed decrease in the selected $\mathrm{CNV}$ area at 3 months. The treatment effects persisted until
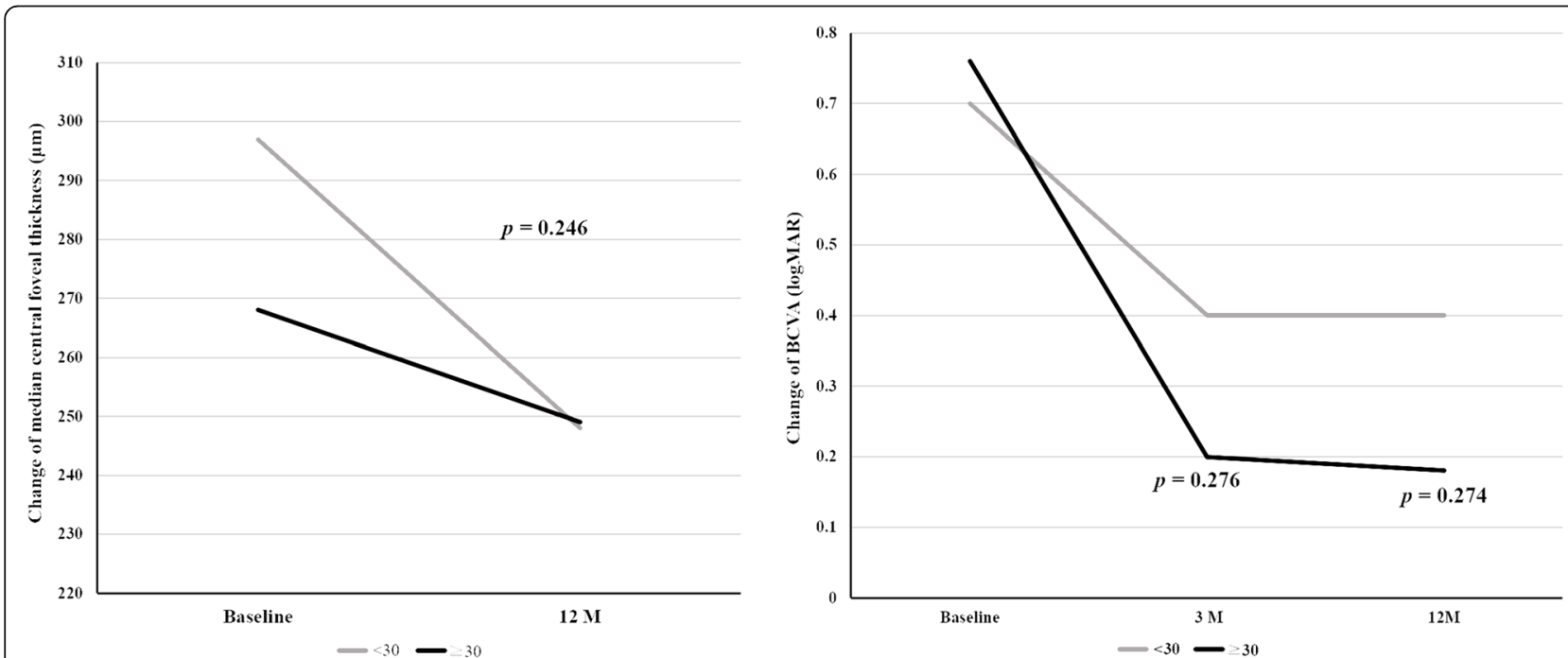

Fig. 3 Both the groups with axial length above or below $30 \mathrm{~mm}$ displayed improvement in the median central foveal thickness and bestcorrected visual acuity (logMAR). The Mann-Whitney $U$ test revealed that the improvement in median central foveal thickness and the median BCVA (logMAR), in both the groups at the third and twelfth months, were not statistically significant 


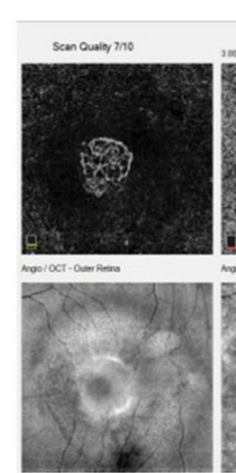

(a)

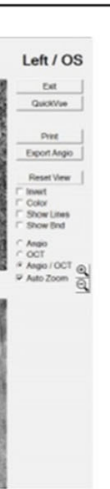

(b)

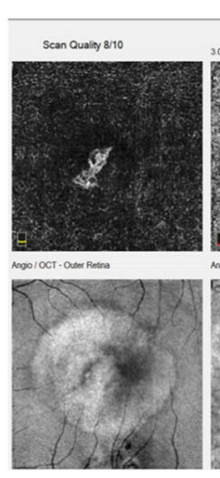

(b)

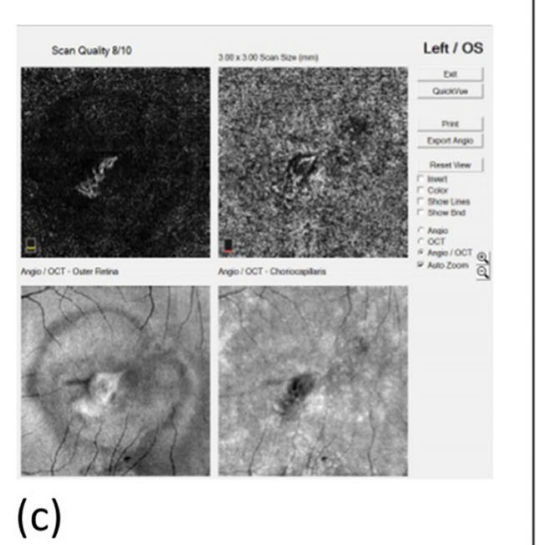

(c)

Fig. 4 Changes in the interlacing CNV after intravitreal aflibercept injection, detected through OCTA images. a Dense, hyperintense vascularity with well-circumscribed, interlacing appearance was observed before treatment. $\mathbf{b}$ One month after treatment, the lesion displayed shrinkage in peripheral vascularity and reduction in the vessel density. c After 12 months, the CNV lesion displayed a greater decrease in the size and vessel density

the twelfth month. Nine in twelve patients displayed decrease in the selected CNV flow area at 3 months after aflibercept injection. While eleven in twelve patients displayed decrease in the selected $\mathrm{CNV}$ flow area at 12 months after aflibercept injection (Table 5). The decrease of selected CNV area and flow area after aflibercept injection is consistent with the results reported by Cheng et al., wherein myopic CNV was treated using intravitreal ranibizumab injection [19].

According to a previous study, it was often considered that active CNV presented as retinal hemorrhage, intraretinal fluid, sub-retinal fluid, or pigment epithelial detachment, as shown by the fundus photography and OCT B-scan images. These active CNV lesions were also considered to be more sensitive to anti-VEGF therapy.
However, some cases of myopic CNV that presented with scars or fibrosis on fundoscopic examinations after anti-VEGF treatment could also show residual, high reflective neovascularization lesions on OCT B-scan images. The aforementioned condition often confused clinicians regarding the necessity for further treatment and the presence of CNV activity. Hence, OCTA is expected to provide additional biomarkers and parameters to guide further management.

Bruyère et al. used OCTA to identify two types of neovascular membranes in high myopia. The first involved small, disorganized vascular loops, suggesting an immature neovascular network. The second is a larger, highly structured, interlacing network, suggesting a mature lesion [21]. Querques et al. reported that on OCTA

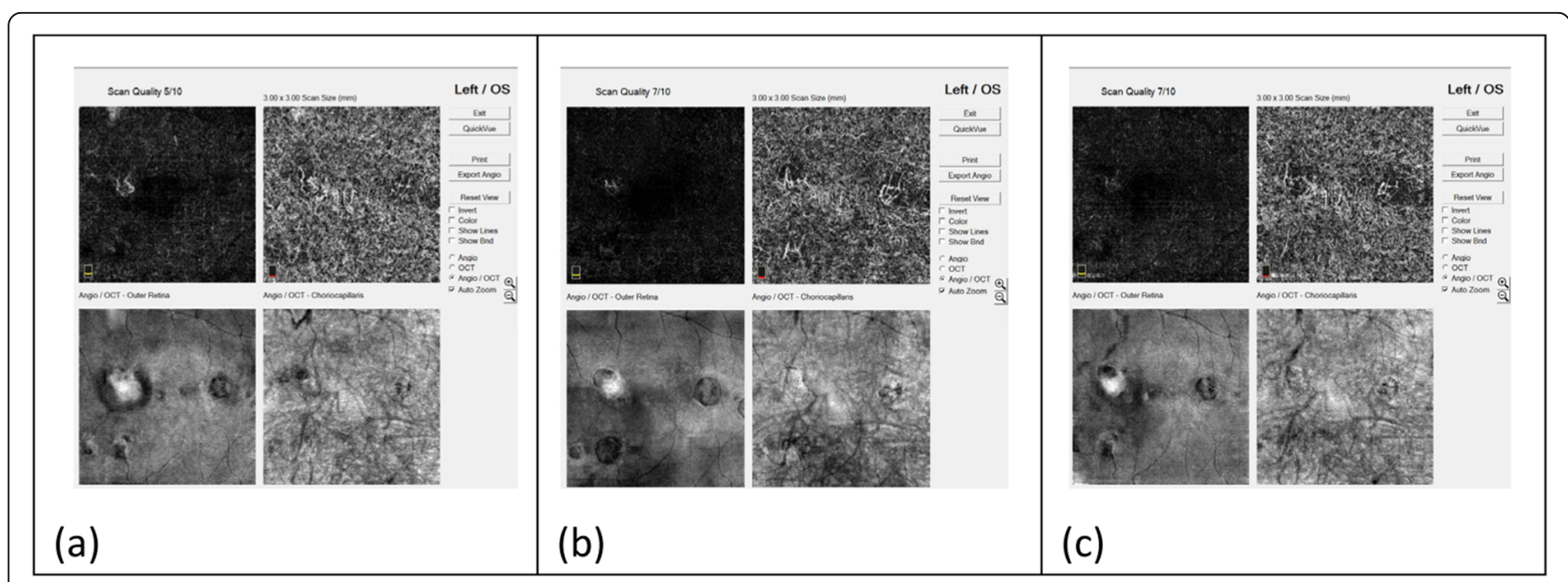

Fig. 5 Changes in the disorganized CNV after intravitreal aflibercept injection, detected through OCTA images. a A small, high-flow network, harboring a vascular, loop-like pattern with no obvious capillary ends was observed before treatment. $\mathbf{b}$ One month after treatment, the lesion displayed shrinkage and reduction in vessel density. c After 12 months, the CNV lesion displayed a greater decrease in the size and vessel density 
Table 5 Demographic characteristics and changes in the features pertaining to OCTA images after aflibercept treatment in patients with myopic CNV

\begin{tabular}{|c|c|c|c|c|c|c|c|c|c|c|c|c|c|c|}
\hline \multirow{2}{*}{$\begin{array}{l}\text { CNV } \\
\text { Pattern } \\
\text { Time }^{a}\end{array}$} & \multirow[t]{2}{*}{ No. } & \multirow[t]{2}{*}{ Age } & \multirow[t]{2}{*}{$\begin{array}{l}\text { Injection } \\
\text { time }\end{array}$} & \multicolumn{2}{|c|}{$\begin{array}{l}\text { CFT } \\
(\mathrm{mm})\end{array}$} & \multicolumn{3}{|c|}{ BCVA } & \multicolumn{3}{|c|}{$\begin{array}{l}\text { CNV area } \\
\left(\mathrm{mm}^{2}\right)\end{array}$} & \multicolumn{2}{|c|}{$\begin{array}{l}\text { CNV flow area } \\
\left(\mathrm{mm}^{2}\right)\end{array}$} & \multirow[b]{2}{*}{$12 \mathrm{M}(\Delta)$} \\
\hline & & & & Pre & $12 \mathrm{M}(\Delta)$ & Pre & $3 \mathrm{M}(\Delta)$ & $12 \mathrm{M}(\Delta)$ & Pre & $3 \mathrm{M}(\Delta)$ & $12 \mathrm{M}(\Delta)$ & Pre & $3 \mathrm{M}(\Delta)$ & \\
\hline Interlacing & 1 & 48 & 1 & 302 & $193(-109)$ & 1.48 & $0.7(-0.78)$ & $0.7(-0.78)$ & 0.701 & $0.656(-0.05)$ & $0.406(-0.29)$ & 0.296 & $0.407(0.11)$ & $0.267(-0.03)$ \\
\hline Interlacing & 2 & 58 & 1 & 271 & $238(-33)$ & 0.7 & $0.4(-0.30)$ & $0.4(-0.30)$ & 0.402 & $0.336(-0.07)$ & $0.259(-0.14)$ & 0.266 & $0.265(0.00)$ & $0.228(-0.04)$ \\
\hline Interlacing & 3 & 20 & 2 & 305 & $211(-94)$ & 0.3 & $0.31(0.01)$ & $0.46(0.16)$ & 0.96 & $0.854(-0.11)$ & $0.739(-0.22)$ & 0.782 & $0.658(-0.12)$ & $0.610(-0.17)$ \\
\hline Interlacing & 4 & 24 & 1 & 355 & $249(-106)$ & 1.3 & $0.2(-1.10)$ & $0.05(-1.25)$ & 0.641 & $0.245(-0.40)$ & $0.168(-0.47)$ & 0.389 & $0.13(-0.26)$ & $0.146(-0.24)$ \\
\hline Interlacing & 5 & 29 & 2 & 286 & $230(-56)$ & 0.5 & $0.16(-0.34)$ & $0.16(-0.34)$ & 0.484 & $0.202(-0.28)$ & $0.172(-0.31)$ & 0.296 & $0.148(-0.15)$ & $0.160(-0.14)$ \\
\hline Interlacing & 6 & 46 & 1 & 261 & $188(-73)$ & 0.5 & $0.2(-0.30)$ & $0.1(-0.40)$ & 0.846 & $0.668(-0.18)$ & $0.656(-0.19)$ & 0.674 & $0.459(-0.22)$ & $0.459(-0.22)$ \\
\hline Disorganized & 7 & 46 & 3 & 302 & $193(-109)$ & 1.48 & $0.7(-0.78)$ & $0.7(-0.78)$ & 0.061 & $0.034(-0.03)$ & $0.018(-0.04)$ & 0.026 & $0.018(-0.01)$ & $0.008(-0.02)$ \\
\hline Disorganized & 8 & 48 & 1 & 282 & $250(-32)$ & 0.7 & $0.16(-0.54)$ & $0.16(-0.54)$ & 0.119 & $0.088(-0.03)$ & $0.075(-0.04)$ & 0.067 & $0.046(-0.02)$ & $0.038(-0.03)$ \\
\hline Disorganized & 9 & 51 & 1 & 222 & $226(4)$ & 0.5 & $0.4(-0.10)$ & $0.4(-0.10)$ & 0.166 & $0.077(-0.09)$ & $0.054(-0.11)$ & 0.131 & $0.054(-0.08)$ & $0.047(-0.08)$ \\
\hline Disorganized & 10 & 62 & 2 & 362 & 407 (45) & 1.78 & $0.5(-1.28)$ & $0.5(-1.28)$ & 0.161 & $0.097(-0.06)$ & $0.067(-0.09)$ & 0.136 & $0.071(-0.07)$ & $0.039(-0.10)$ \\
\hline Disorganized & 11 & 63 & 2 & 297 & $267(-30)$ & 0.4 & $0.3(-0.10)$ & $0.2(-0.20)$ & 0.077 & $0.06(-0.02)$ & $0.032(-0.05)$ & 0.022 & $0.021(-0.00)$ & $0.02(-0.002)$ \\
\hline Disorganized & 12 & 76 & 3 & 281 & $248(-33)$ & 1 & $0.16(-0.84)$ & $0.16(-0.84)$ & 0.088 & $0.053(-0.04)$ & $0.055(-0.03)$ & 0.037 & $0.043(0.01)$ & $0.033(-0.004)$ \\
\hline
\end{tabular}

BCVA best-corrected visual acuity, CFT central foveal thickness, CNV choroidal neovascularization, logMAR logarithm of the minimum angle of resolution, $M$ month, Pre Pre-treatment, $(\Delta)$ Changes compared with baseline before aflibercept treatment

a 3 : three months after aflibercept treatment; $12 \mathrm{M}$ : twelve months after aflibercept treatment

images, active myopic CNVs could be mainly interlacing, whereas the abnormal vascular network with tangled pattern could be inactive myopic CNV [30]. Cheng et al. reported that sea-fan and lacy-wheel types tend to be clinically active CNVs, whereas poorly defined lesions, such as filamentous $\mathrm{CNV}$ vessels, could be either active or inactive.

In the present study, the interlacing group displayed a trend towards better improvement in CFT reduction and decrease in the selected $\mathrm{CNV}$ area and flow area (Table 5) (Fig. 6(a)(b)). Additionally, previous studies have reported consistent results and stated that the capillaries and small caliber feeder vessels were significantly attenuated after intravitreal ranibizumab injection, whereas the main central trunk vessel and large caliber feeder vessels remained unchanged [22, 31].

However, owing to the limited sample size, the scenario warrants further investigation to clarify the significance of $\mathrm{CNV}$ patterns in predicting the response to anti-VEGF therapy. OCTA could be considered as a useful tool that can be employed to identify the different $\mathrm{CNV}$ patterns and detect $\mathrm{CNV}$ activity, predict treatment response, and monitor the need for repeated treatments in patients with myopic CNV.

The current study has certain limitations. The series was relatively small, and the duration of follow-up was short. The present study observed some poor image quality with significant motion artifacts, due to unstable
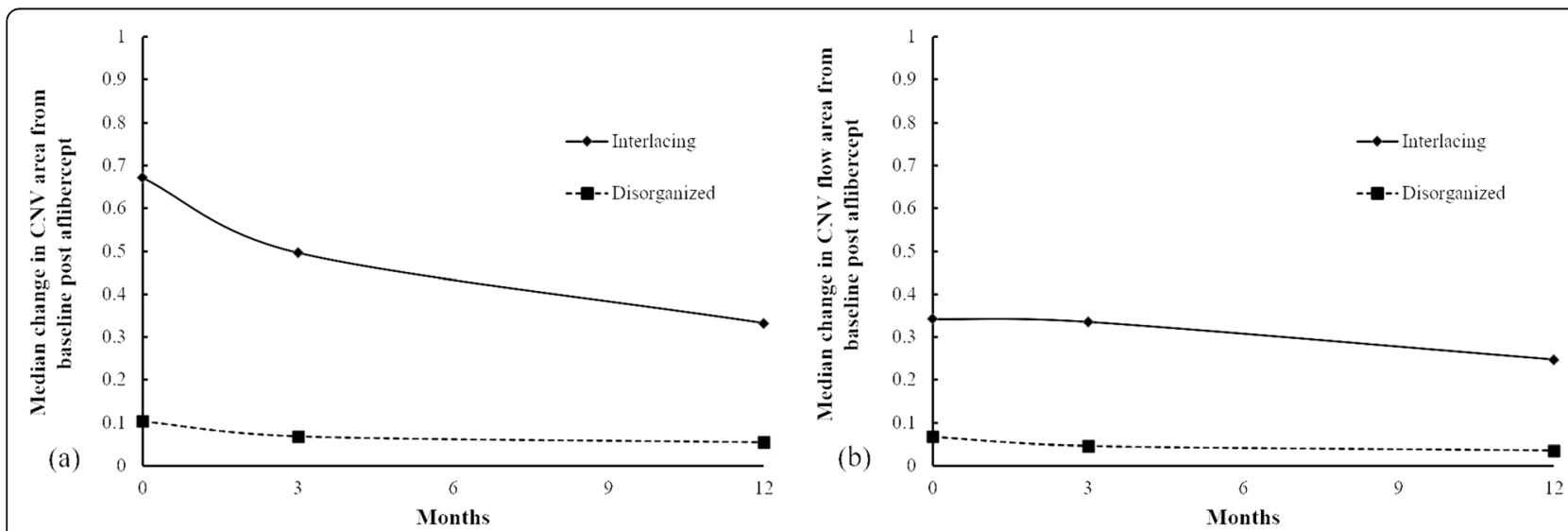

Fig. $\mathbf{6}$ a, b Three months after the aflibercept injection, a decrease in both the CNV area and flow area were observed in both interlacing and disorganized patern and the treatment effects persisted until the twelfth month. Figure $6 \mathbf{a}$. Much more decrease in the CNV area and flow area, at the third and twelfth months, were observed in interlacing pattern 
fixation, which could make the analysis more challenging. Similarly, the accuracy of the layers automatically divided by OCTA could be affected by the long axial length of the pathologic myopia eyeballs.

\section{Conclusion}

In conclusion, the administration of a single injection of intravitreal aflibercept $2.0 \mathrm{mg}$ at the baseline in patients with myopic CNV showed effective results. A single aflibercept injection was observed to resolve myopic $\mathrm{CNV}$ in approximately half of the patients. The median number of injections was two injections within 12 months.

Eyes with the interlacing pattern on OCTA displayed a greater decrease in size and flow after intravitreal aflibercept.

Further studies with large sample sizes and longer follow-ups are necessary to explore the relationship between different $\mathrm{CNV}$ patterns, detected through OCTA, and the therapeutic effects of anti-VEGF on myopic $\mathrm{CNV}$.

\section{Abbreviations \\ CNV: Choroidal neovascularization; PDT: Photodynamic therapy: VEGFs: Vascular endothelial growth factors; OCT: Optical coherence tomography; OCTA: Optical coherence tomography angiography; SD- OCT: Spectral-domain optical coherence tomography; BCVA: Best-corrected visual acuity; logMAR: Logarithm of the minimum angle of resolution; CFT: Central foveal thickness; IQR: Interquartile range; SD: Standard deviation}

\section{Acknowledgements}

Not applicable.

\section{Authors' contributions}

SL Chen, PL Tang, and TT Wu analyzed and interpreted the result of intravitreal aflibercept injection for myopic choroidal neovascularization patient. SL Chen was a major contributor in writing the manuscript. All authors read and approved the final manuscript.

\section{Authors' information}

Not applicable.

\section{Funding}

This research received no specific grant from any funding agency in the public, commercial, or not-for-profit sectors.

\section{Availability of data and materials}

The datasets used and/or analysed during the current study are available from the corresponding author on reasonable request.

\section{Declarations}

\section{Ethics approval and consent to participate}

Informed consent was obtained from all the patients. The study program was reviewed and approved by the Institutional Review Board of the Kaohsiung Veterans General Hospital (KSVGH21-CT1-17). In the following study, all methods were performed in accordance with the relevant guidelines and regulations.

\section{Consent for publication}

Not applicable.

\section{Competing interests}

The authors declare that they have no competing interests.

\section{Author details}

'Department of Ophthalmology, Kaohsiung Veterans General Hospital, No.386, Dazhong 1st Rd., Zuoying Dist., 813 Kaohsiung, Taiwan. ${ }^{2}$ Section of Research Center of Medical Informatics, Kaohsiung Veterans General Hospital, Kaohsiung, Taiwan. ${ }^{3}$ School of Medicine, National Yang Ming University, Taipei, Taiwan.

Received: 13 January 2021 Accepted: 27 August 2021

Published online: 22 September 2021

\section{References}

1. Alia Rashid HEG. Update on the pathology of pathological myopia. Pathol Myopia. 2014:83-95. https://doi.org/10.1007/978-1-4614-8338-0_7.

2. Ohno-Matsui K, Lai TY, Lai CC, Cheung CM. Updates of pathologic myopia. Prog Retin Eye Res. 2016;52:156-87. https://doi.org/10.1016/.jpreteyeres.201 5.12.001.

3. Wong TY, Ferreira A, Hughes R, Carter G, Mitchell P. Epidemiology and disease burden of pathologic myopia and myopic choroidal neovascularization: an evidence-based systematic review. Am J Ophthalmol. 2014;157(1):9-25 e12. https://doi.org/10.1016/j.ajo.2013.08.010.

4. Iwase A, Araie M, Tomidokoro A, Yamamoto T, Shimizu H, Kitazawa Y, et al. Prevalence and causes of low vision and blindness in a Japanese adult population: the Tajimi study. Ophthalmology. 2006;113(8):1354-62. https:// doi.org/10.1016/j.ophtha.2006.04.022

5. Yamada M, Hiratsuka Y, Roberts CB, Pezzullo ML, Yates K, Takano S, et al. Prevalence of visual impairment in the adult Japanese population by cause and severity and future projections. Ophthalmic Epidemiol. 2010;17(1):50-7. https://doi.org/10.3109/09286580903450346.

6. Wong TY, Foster PJ, Hee J, Ng TP, Tielsch JM, Chew SJ, et al. Prevalence and risk factors for refractive errors in adult Chinese in Singapore. Invest Ophthalmol Vis Sci. 2000;41(9):2486-94.

7. Yoshida T, Ohno-Matsui K, Ohtake Y, Takashima T, Futagami S, Baba T, et al. Long-term visual prognosis of choroidal neovascularization in high myopia: a comparison between age groups. Ophthalmology. 2002;109(4):712-9. https://doi.org/10.1016/S0161-6420(01)01007-7.

8. Curtin BJ, Karlin DB. Axial length measurements and fundus changes of the myopic eye. I. The posterior fundus. Trans Am Ophthalmol Soc. 1970;68:312-34.

9. Hayashi K, Ohno-Matsui K, Shimada N, et al. Long-term pattern of progression of myopic maculopathy: a natural history study. Ophthalmology. 2010;117(8):1595-611 1611 e1591-1594.

10. Neelam K, Cheung CM, Ohno-Matsui K, Lai TY, Wong TY. Choroidal neovascularization in pathological myopia. Prog Retin Eye Res. 2012;31(5): 495-525. https://doi.org/10.1016/j.preteyeres.2012.04.001.

11. Ikuno Y, Nagai Y, Matsuda S, Arisawa A, Sho K, Oshita T, et al. Two-year visual results for older Asian women treated with photodynamic therapy or bevacizumab for myopic choroidal neovascularization. Am J Ophthalmol. 2010;149(1):140-6. https://doi.org/10.1016/j.ajo.2009.08.008.

12. Nakanishi H, Tsujikawa A, Yodoi Y, Ojima Y, Otani A, Tamura H, et al. Prognostic factors for visual outcomes 2-years after intravitreal bevacizumab for myopic choroidal neovascularization. Eye. 2011;25(3):375-81. https://doi. org/10.1038/eye.2010.226.

13. Wakabayashi T, Ikuno Y, Gomi F, Hamasaki T, Tano Y. Intravitreal bevacizumab vs sub-tenon triamcinolone acetonide for choroidal neovascularization attributable to pathologic myopia. Am J Ophthalmol. 2009:148(4):591-6 e591. https://doi.org/10.1016/j.ajo.2009.05.026.

14. Tufail A, Narendran N, Patel PJ, Sivaprasad S, Amoaku W, Browning AC, et al. Ranibizumab in myopic choroidal neovascularization: the 12-month results from the REPAIR study. Ophthalmology. 2013;120(9):1944-5 e1941. https:// doi.org/10.1016/j.ophtha.2013.06.010.

15. Tufail A, Patel PJ, Sivaprasad S, Amoaku W, Browning AC, Cole M, et al. Ranibizumab for the treatment of choroidal neovascularisation secondary to pathological myopia: interim analysis of the REPAIR study. Eye. 2013;27(6): 709-15. https://doi.org/10.1038/eye.2013.8.

16. Wolf S, Balciuniene VJ, Laganovska G, Menchini U, Ohno-Matsui K, Sharma T, et al. RADIANCE: a randomized controlled study of ranibizumab in patients with choroidal neovascularization secondary to pathologic myopia. Ophthalmology. 2014;121(3):682-92 e682. https://doi.org/10.1016/j.ophtha.2 013.10.023.

17. Pece A, Milani P. Intravitreal aflibercept for myopic choroidal neovascularization. Graefes Arch Clin Exp Ophthalmol. 2016;254(12):2327-32. https://doi.org/10.1007/s00417-016-3396-9. 
18. Ikuno Y, Ohno-Matsui K, Wong TY, Korobelnik JF, Vitti R, Li T, et al. Intravitreal Aflibercept injection in patients with myopic choroidal neovascularization: the MYRROR study. Ophthalmology. 2015;122(6):1220-7. https://doi.org/10.1016/j.ophtha.2015.01.025.

19. Cheng Y, Li Y, Huang X, Qu Y. Application of optical coherence tomography angiography to assess anti-vascular endothelial growth factor therapy in myopic choroidal neovascularization. Retina. 2019;39(4):712-8. https://doi. org/10.1097/IAE.0000000000002005.

20. Muakkassa NW, Chin AT, de Carlo T, Klein KA, Baumal CR, Witkin AJ, et al. Characterizing the effect of anti-vascular endothelial growth factor therapy on treatment-naive choroidal neovascularization using optical coherence tomography angiography. Retina. 2015;35(11):2252-9. https://doi.org/10.1 097/IAE.00000000000000836.

21. Bruyere E, Miere A, Cohen SY, et al. Neovascularization secondary to high myopia imaged by optical coherence tomography angiography. Retina. 2017;37(11):2095-101. https://doi.org/10.1097//AE.0000000000001456.

22. Querques L, Giuffre C, Corvi F, et al. Optical coherence tomography angiography of myopic choroidal neovascularisation. Br J Ophthalmol. 2017; 101(5):609-15. https://doi.org/10.1136/bjophthalmol-2016-309162.

23. Brue C, Pazzaglia A, Mariotti C, Reibaldi M, Giovannini A. Aflibercept as primary treatment for myopic choroidal neovascularisation: a retrospective study. Eye. 2016;30(1):139-45. https://doi.org/10.1038/eye.2015.199.

24. Brown DM, Heier JS, Clark WL, Boyer DS, Vitti R, Berliner AJ, et al. Intravitreal aflibercept injection for macular edema secondary to central retinal vein occlusion: 1-year results from the phase 3 COPERNICUS study. Am J Ophthalmol. 2013;155(3):429-37 e427. https://doi.org/10.1016/j.ajo.2012.09.026.

25. Chen Y, Sharma T, Li X, Song Y, Chang Q, Lin R, et al. Ranibizumab versus verteporfin photodynamic therapy in Asian patients with myopic choroidal neovascularization: brilliance, a 12-month, randomized, double-masked study. Retina. 2019;39(10):1985-94. https://doi.org/10.1097//AE. 0000000000002292.

26. Baba T, Kubota-Taniai M, Kitahashi M, Okada K, Mitamura Y, Yamamoto S. Two-year comparison of photodynamic therapy and intravitreal bevacizumab for treatment of myopic choroidal neovascularisation. $\mathrm{Br} J$ Ophthalmol. 2010;94(7):864-70. https://doi.org/10.1136/bjo.2009.166025.

27. Farinha CL, Baltar AS, Nunes SG, Franqueira NF, Figueira JP, Pires IA, et al. Choroidal thickness after treatment for myopic choroidal neovascularization Eur J Ophthalmol. 2013;23(6):887-98. https://doi.org/10.5301/ejo.5000323.

28. Huang D, Swanson EA, Lin CP, Schuman J, Stinson W, Chang W, et al. Optical coherence tomography. Science. 1991;254(5035):1178-81. https:// doi.org/10.1126/science.1957169.

29. Litts KM, Ach T, Hammack KM, Sloan KR, Zhang Y, Freund KB, et al. Quantitative analysis of outer retinal tubulation in age-related macular degeneration from spectral-domain optical coherence tomography and histology. Invest Ophthalmol Vis Sci. 2016;57(6):2647-56. https://doi.org/1 0.1167/iovs.16-19262.

30. Jia Y, Bailey ST, Wilson DJ, Tan O, Klein ML, Flaxel CJ, et al. Quantitative optical coherence tomography angiography of choroidal neovascularization in age-related macular degeneration. Ophthalmology. 2014;121(7):1435-44. https://doi.org/10.1016/j.ophtha.2014.01.034.

31. Huang D, Jia Y, Rispoli M, Tan O, Lumbroso B. Optical coherence tomography angiography of time course of choroidal neovascularization in response to anti-angiogenic treatment. Retina. 2015;35(11):2260-4. https:// doi.org/10.1097//AE.0000000000000846.

\section{Publisher's Note}

Springer Nature remains neutral with regard to jurisdictional claims in published maps and institutional affiliations.

Ready to submit your research? Choose BMC and benefit from:

- fast, convenient online submission

- thorough peer review by experienced researchers in your field

- rapid publication on acceptance

- support for research data, including large and complex data types

- gold Open Access which fosters wider collaboration and increased citations

- maximum visibility for your research: over $100 \mathrm{M}$ website views per year

At BMC, research is always in progress.

Learn more biomedcentral.com/submissions 